УДК 621.565 .58

H.B. Жихарєва

Одеська національна академія харчових технологій, вул. Дворянська, 1/3, Одеса, 65082

\title{
МАТЕМАТИЧНІ АСПЕКТИ ТЕРМОЕКОНОМІЧНОГО АНАЛІЗУ ХОЛОДИЛЬНОЇ УСТАНОВКИ ПЛОДООВОЧЕСХОВИЩА
}

Розглянуто математичні аспекти термоекономічного аналізу режиму роботи холодильної установки плодоовочесховищ. Визначено величини потоків ексергї та ексергетичних втрат на прикладі холодильної установки безпосереднього охолодження.

Ключові слова: оптимізація - режими роботы - холодильна установка - термоекономічна модель - ексергія - ексергетичні втрати.

\section{Н.В. Жихарева}

Одесская национальная академия пищевых технологий, ул. Дворянская, 1/3, Одесса, 65082

\section{МАТЕМАТИЧЕСКИЕ АСПЕКТЫ ТЕРМОЕКОНОМИЧЕСКОГО АНАЛИЗА ХОЛОДИЛЬ- НОЙ УСТАНОВКИ ПЛОДООВОЩЕХРАНИЛИЩА}

\begin{abstract}
Рассмотрены математические аспекты термоекономического анализа режима работы холодильной установки плодоовощзехранилищ. Определены величины потоков эксергиии и эксергетических потерь на примере холодильной установки непосредственного охлаждения.
\end{abstract}

Ключевые слова: оптимизация - режимы работы - холодильная установка - термоекономическая модель - эксергия-эксергетические потери.

\section{I. ВСТУП}

Оптимізація режиму роботи холодильної установки плодоовочесховищ базується на конкуруючих властивостях системи [1,2]. Збільшення температурних напорів в теплообмінних апаратах приводить до скорочення капітальних витрат і одночасного збільшення витрати енергії, тобто до збільшення змінної частини експлуатаційних витрат, і навпаки.

Використовуючи метод термоекономічного аналізу можливо визначити оптимальний режим роботи холодильної установки у зв'язку із широким діапазоном можливих змін температур охолоджуючого об'єкту та зовнішнього середовища.

На підставі методу термоекономічного аналізу та ексергетичних розрахунків технічних систем $[1,4]$ розроблено термоекономічну модель оптимізації режимів роботи холодильної установки плодоовочесховищ, в якій вперше враховані особливості конструктивних елементів повітроохолоджувачів 3 урахуванням технологічних та економічних критеріїв оптимальності та в якій температурний напір та зміна температури середовищ, що охолоджується або нагрівається, в одному теплообмінному апараті використанні як залежні змінні.

Для оптимізації таких складних систем, як холодильні установки, можна використовувати метод термоекономічного аналізу[1]. Головна ідея методу полягає в побудові термоекономічної моделі, що дозволяє представити замкнену схему холодильної установки зі зворотними зв'язками у вигляді ланцюжка окремих зон або розгалуженого ланцюжка, що значно спрощує розрахунки Термоекономічна модель холодильної установки відображає зміни i перетворення основного потоку ексергії, що забезпечує здобуття кінцевого ефекту - мінімум приведених витрат.

\section{II МАТЕМАТИЧНІ АСПЕКТИ МІНІМІЗАЦІї ПРИВЕДЕНИХ ВИТРАТ}

Методика мінімізації величини приведених витрат (ПВ) істотно залежить від ступеня складності холодильної установки. Установки, що використовують проміжний теплоносій, як правило, описуються в процесі оптимізації чотирма або більшою кількістю незалежних параметрів. У цьому випадку можна застосовувати відомі методи мінімізації, зокрема, методи сполучених напрямків [4] або метод Лагранжа [3,5]. Якщо ж розглядається установка 3 безпосереднім випаровуванням 3 оборотною системою водопостачання (рисунок 1).

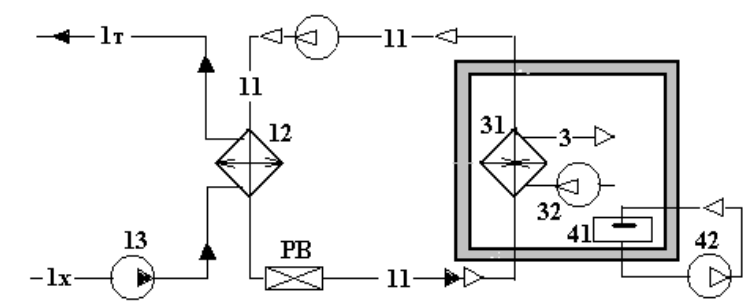

Рисунок 1 - Схема одноступеневої холодильної установки безпосереднього охолодження 
Від зовнішнього джерела до системи підводиться енергія (ексергія) із ціною Цел, (грн/кВтгодину) для приводу електродвигуна компресора $\mathrm{e}_{11}$, електродвигуна насосу охолоджувальногосередовища $\mathrm{e}_{13}$, електродвигуна вентилятора повітроохолоджувача ез2, електродвигуна насосу плівкового зволожувача ен2. Від зовнішнього джерела підводиться також охолоджена вода в кількості $\mathrm{V}_{12}, \mathrm{~m}^{3}$ /годину, ціною Ц стеми передається ексергія із зони 1 у зону $3-\mathrm{e}_{3}$, 3 ціною одиниці ексергії $\lambda_{3} \mathrm{У}$ результаті роботи системи має бути отримана обрана холодопродуктивність е ехл.

Режим роботи холодильної установки описується двома основними незалежними параметрами. Враховуючи мале число параметрів, доцільно застосовувати метод Нелдера-Міда. Це означає, що пошук мінімуму ведеться за допомогою послідовного визначення всіх складових цільової функції, 3 врахуванням залежних змінних на відміну від методу Лагранжа, який використовує похідну.

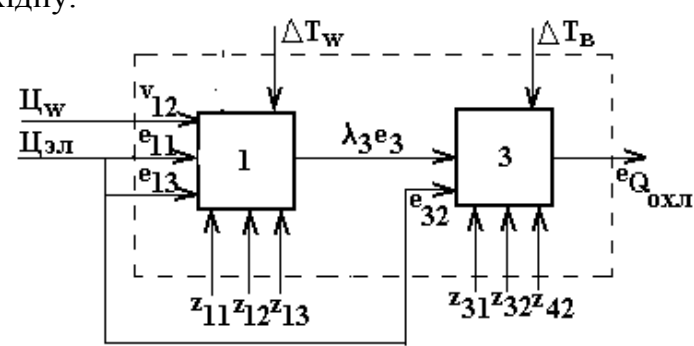

Рисунок 2 - Термоекономічна модель одноступеневої холодильної установки безпосереднього охолодження

Критерієм оптимізації обрані приведені витрати (ПВ), які для для установки безпосереднього випаровування можуть бути описані виразом $[4,5,6]$ :

$\Pi B=\left(Ц_{е л}\left(\mathrm{e}_{11}+\mathrm{e}_{13}+\mathrm{e}_{32}+\mathrm{e}_{42}\right)+Ц_{\mathrm{w}} \mathrm{V}_{12}+\left(\mathrm{z}_{11}+\mathrm{z}_{12}+\right.\right.$ $\left.\mathrm{z}_{31}+\mathrm{z}_{32}+\mathrm{z}_{42}\right) \tau_{\mathrm{p}}$

де Цел-вартість електроенергії (грн/кВт-годину); $\bigsqcup_{\text {w- вартість води грн/м }}{ }^{3}, \mathrm{~V}_{12}$ - щосекундна витрата води в конденсаторі $\mathrm{m}^{3}$ /годину; е $\mathrm{e}_{11}$ - ексергія, що споживається електродвигуном компресора; $\mathrm{e}_{13}$ - ексергія, що споживається електродвигуном водяного насоса е е - ексергія, що споживається електродвигуном вентилятора повітроохолоджувача; е 42 - ексергія, що споживається електродвигуном насосу парового зволожувача; $\mathrm{Z}_{11}, \mathrm{Z}_{12}, \mathrm{Z}_{13}$, $\mathrm{Z}_{31}, \mathrm{Z}_{32}, \mathrm{Z}_{42}$ - нормативні відрахування від вартості та витрати на ремонт і експлуатацію відповідного обладнання, тр - кількість робочих годин у рік. (рисунок 2).

При отриманому значенні $\mathrm{Q}_{\text {охл }}$ $\Pi \mathrm{B}=\Pi \mathrm{B}\left(\Delta T_{\mathrm{w}}, \Delta T_{\mathrm{B}}\right)$.

3 обмеженнями: $\Theta_{\mathrm{K}}=\mathrm{f}\left(\Delta \mathrm{T}_{\mathrm{w}}\right)$ та $\Theta_{0}=\mathrm{f}\left(\Delta \mathrm{T}_{\mathrm{B}}\right)$ тут $\Theta_{\mathrm{K}}, \Theta_{0}$ - температурні напори в конденсаторі та охолоджувачі, які $є$ залежними змінними від $\Delta \mathrm{T}_{\mathrm{w}}$ та $\Delta \mathrm{T}_{\mathrm{B}}, \Delta \mathrm{T}_{\mathrm{w}}-$ перепад температур у конденсаторі; $\Delta \mathrm{T}_{\text {в }}$ - перепад температур повітря в повітроохолоджувачі.

Цільова функція була розв'язана методом послідовних наближень Нелдера - Міда. За даних, які входять на цьому етапі оптимізації, виведені математичні залежності для розрахунку всіх складових цільової функції, з урахуванням ексергетичних втрат, як критерію термоекономічної ефективності. Визначені проміжні вартості ексергії між зонами. ностями:

Термоекономічна модель описана залеж-

$\mathrm{e}_{11}=\mathrm{E}_{11}\left(\mathrm{e}_{3}, \Theta_{\mathrm{K}}, \Delta T_{\mathrm{w}}\right) ; \mathrm{e}_{13}=\mathrm{E}_{13}\left(\mathrm{e}_{1}, \Theta_{\mathrm{K}}, \Delta T_{\mathrm{w}}\right) ;$

$\mathrm{e}_{31}=\mathrm{E}_{31}\left(\mathrm{e}_{\text {охл }}, \Theta_{0}, \Delta T_{\mathrm{B}}\right) ; \mathrm{e}_{32}=\mathrm{E}_{13}\left(\mathrm{e}_{\text {охл }}, \Delta T_{\mathrm{B}}\right) ;$

$\mathrm{e}_{41}=\mathrm{E}_{41}\left(\mathrm{e}_{\text {охл }}, \Theta_{0}, \Delta T_{\mathrm{B}}\right) ; \mathrm{e}_{42}=\mathrm{E}_{13}\left(\mathrm{e}_{\text {охл }}, \Delta T_{\mathrm{B}}\right)$;

$\mathrm{Z}_{13}=\mathrm{Z}_{13}\left(\mathrm{e}_{1}, \Theta_{\mathrm{K}}, \Delta T_{\mathrm{w}}\right) ; \mathrm{z}_{11}=\mathrm{Z}_{11}\left(\mathrm{e}_{1}, \Theta_{\mathrm{K}}, \Delta T_{\mathrm{w}}\right) ;$

$\mathrm{Z}_{12}=\mathrm{Z}_{12}\left(\mathrm{e}_{1}, \Theta_{\mathrm{\kappa}}, \Delta T_{\mathrm{w}}\right) ; \mathrm{z}_{31}=\mathrm{Z}_{31}\left(\mathrm{e}_{\text {охл }}, \Theta_{0}, \Delta T_{\mathrm{в}}\right)$;

$\mathrm{v}_{12}=\mathrm{V}_{12}\left(\mathrm{e}_{3}, \Theta_{\mathrm{K}}, \Delta T_{\mathrm{w}}\right)$;

Величини потоків ексергії, яка зв'язує зони:

$$
\begin{aligned}
& \mathrm{e}_{3}=\mathrm{E}_{3}\left(\mathrm{e}_{\text {охл }}, \Theta_{0}, \Delta \mathrm{T}_{\mathrm{в}}\right) ; \\
& \mathrm{e}_{\text {охл }}=\mathrm{E}_{\mathrm{o}}\left(\mathrm{Q}_{\text {охл }}, \mathrm{T}_{\text {охл }}, \mathrm{T}_{\text {ос }}\right)
\end{aligned}
$$

Для визначення термодинамічних параметрів (питомий обсяг, тиск конденсації і кипіння, ентальпія у точках термодинамічного циклу, різниця ентальпій в процесе стиснення, тепла і конденсації і т.д) використані емпіричні рівняння.

Система рівнянь (3), (4) була розв'язана методом послідовних наближень Нелдера - Міда, за яким виведені формули для визначення складових критерія оптимізації (1).

Оптимізація режиму роботи холодильної установки $€$ завершальним етапом комплексної оптимізації системи охолодження плодоовочесховищ.

За даних, які входять на цьому етапі оптимізації, виведені математичні залежності для розрахунку всіх складових цільової функції, з урахуванням ексергетичних втрат, як критерію термодинамічної ефективності.Визначені проміжні вартості ексергії між зонами.

Для оптимізації холодильної установки врахований оптимальний повітроохолоджувач, який визначений за модульним принципом.[4] Як константа модуля обрана загальна довжина пучка труб, а не загальна зовнішня поверхня, при цьому залишається константою для даного діаметра труби внутрішня поверхня, а зовнішня змінюється за варіації кроку оребрення.

Для визначення температури кипіння тиску хладагенту $\left(\mathrm{T}_{\mathrm{o}}\right)$ розглянемо схему руху тепломасообмінних середовищ в повітроохолоджуачі.

Охолодження повітря в повітроохолоджувачі $\left(\Delta \mathrm{T}_{\mathrm{B}}\right) \epsilon$ незалежною змінною, а температура повітря, що надходить в повітроохолоджувач дорівнює температурі повітря в камері $\left(\mathrm{T}_{\mathrm{B}}=\mathrm{T}_{\text {кам}}\right)$.

Втрата ексергії при необоротному процесі переході теплоти $\left(Q_{\mathrm{o}}\right)$ з рівня температури охолод- 
жуваного об'єкта ( $\left.T_{\text {кам }}\right)$ на рівень середньої температури повітря в повітроохолоджувачі $\left(T_{\mathrm{cв}}\right)$ складе

$$
\Delta e_{\text {охл }}=Q_{\text {oxi }} \cdot\left(\frac{T_{o c}}{T_{c \varepsilon}}-\frac{T_{o c}}{T_{\text {кам }}}\right)
$$

Вираз для зведеної холодопродуктивності установки має вид:

$$
e_{\text {охл }}=Q_{\text {охл }} \cdot\left(\frac{T_{O C}}{\mathrm{~T}_{\text {кам }}}-1\right)
$$

Кількість ексергії, що підводиться до електродвигуна вентилятора повітроохолоджувача від зовнішнього джерела визначаємо за формулою:

$$
e_{B}=\frac{V_{n} \cdot H_{B}}{10^{3} \cdot \eta_{B} \cdot \eta_{B e}}
$$

де витрата повітря через повітроохолоджувач :

$$
V_{n}=\frac{Q_{\text {ox } \pi}}{\rho_{c n} \cdot C_{c n} \cdot \Delta T_{6}}
$$

$H в$ - витрата напору в повутроохолоджувачі, Па. Значення витрати напору визначається за программою оптимізаційного розрахунку повітроохолоджувача.

Вираз для визначення ексергії, яка підводиться до вентилятора повітроохолоджувача від зовнішнього джерела має вигляд:

$$
e_{32}=\frac{Q_{\text {oxл }} \cdot H_{B}}{10^{3 \cdot} \rho_{c n} \cdot \Delta T_{B} \cdot C_{p} \cdot \eta_{B} \cdot \eta_{B e}}
$$

Електродвигуни вентілятора повітроохолоджувача розташовані в межах охолоджуваного об'єкта, тому теплове навантаження повітроохолоджувача повинна бути визначена 3 урахуванням тепла, внесеного електродвигуном:

$$
Q_{\text {во }}=Q_{\text {охл }}+e_{32}
$$

В цьому випадку кількість ексергії, споживаної повітроохолоджувачем визначаємо за формулою:

$$
e_{\text {во }}=\frac{e_{\text {охл }}}{\left(\frac{T_{\text {oc }}}{T_{\text {кам }}}-1\right)} \cdot \frac{H_{B}}{10^{3 \cdot} \rho_{\Pi} \cdot \Delta T_{B} \cdot C_{p} \cdot \eta_{B} \cdot \eta_{B e}-H_{B}}
$$

Втрата ексергіi при необоротному процесі перехода теплоти $\left(\mathrm{Q}_{\text {по }}\right)$ з рівня середньої температури повітря в повітроохолоджувачі $\left(\mathrm{T}_{\text {св }}\right)$ на рівень кипіння хладагента ( $\left.\mathrm{T}_{\text {o }}\right)$ складе:

$$
\Delta e_{\text {во }}=Q_{\text {по }} \cdot\left(\frac{T_{o c}}{T_{0}}-\frac{T_{o c}}{T_{\text {кам }}}\right)
$$

Для розрахованих оптимізованих повітроохолоджувачів для плодоовочесховищ за модульним принципом 3 варіюванням конструктивних параметрів визначають в циклі витрату повітря.

Розрахункове значення об'ємної витрати повітря, яке залежить від значення підохолодження повітря в повітроохолоджувачі $\left(\Delta \mathrm{T}_{\mathrm{B}}\right)$. Значення останього приводить до зменшення площі поверхні $\mathrm{F}_{\text {по }}$ апаратів. Температурний напор є залежною змінною та визнаяається за формулою:

$$
\theta_{o}=\frac{Q_{\text {по }}}{k_{\text {по }} \cdot F_{\text {по }}}
$$

Зменшення площі поверхні $\mathrm{F}_{\text {по }}$ апаратів може бути досягнене за рахунок зниження температури кипіння холодильного агенту.

Втрату ексергії на кожній стадії в конденсаторі визначимо по залежностях:

- зона зняття перегріву:

$$
\Delta e_{\text {пр }}=G \cdot\left(i_{2}-i_{3}\right) \cdot(-1)\left(1-\frac{T_{o c}}{T_{\text {сп2 }}}\right)
$$

- зона конденсації:

$$
\Delta e_{\text {кон }}=G \cdot r_{\kappa} \cdot\left(1-\frac{T_{o c}}{T_{\mathrm{\kappa}}}\right)
$$

- зона переохолодження рідкого холодоагенту:

$$
\Delta e_{\kappa_{\text {пк }}}=G \cdot\left(i_{4}-i_{5}\right)\left(1-\frac{T_{o c}}{T_{\text {сж2 }}}\right)
$$

Вираз для втрат ексергії при дроселюванні через регулюючий вентиль:

$$
\cdot \Delta \boldsymbol{e}_{\text {др }}=G \cdot T_{\text {ос }} \cdot C_{\text {сж1 }}\left(\frac{T_{3}}{T o}-1-\ln \frac{T_{3}}{T_{0}}\right)
$$

Механічні втрати (на тертя) у механізмі компресора визначаються формулою:

$$
\cdot \Delta e_{\mathcal{M}}=P_{\mathrm{tp}} \cdot V_{h}
$$

де $\mathrm{P}_{\text {тр }}$ - питомий тиск сил тертя ( залежно від типу робочого тіла), Па; $\mathrm{Vh}$ - об'єм, описуваний поршнями компресора, $\mathrm{M}^{3} /$ сек.

Кількість ексергії $\mathrm{e}_{11}$, яке повинне бути підведене до електродвигуна компресора (тобто споживана їм потужність) визначиться підсумовуванням потоку ексергії е $\mathrm{e}_{1}$, що виходить із зони 1 i втрат ексергії в цій зоні:

Складаючи ексергію е 3 , що виходить із зони 1, і втрати ексергії в цій зоні, знайдемо ексергію, яку потрібно підвести до електродвигуна компресора (споживана потужність):

$$
e_{11}=\frac{e_{1}+\Delta e_{\text {пр }}+\Delta e_{\text {кпк }}+\Delta e_{\text {кон }}+\Delta e_{\text {др }}+\Delta e_{\text {мк }}}{\eta_{\kappa e}}
$$

де $\eta_{\text {ке }}$ - коефіцієнт корисної дії. електродвигуна компресора і його передачі.

Потужність, споживану електродвигуном насоса 13 визначимо за формулою:

$$
e_{13}=\frac{Q_{K} \cdot H_{w}}{\left(c_{w} \cdot \gamma_{w} \cdot \Delta T_{w} \cdot \eta_{w}-b_{1} \cdot H_{w}\right) \cdot \eta_{\text {дв }}}
$$

де b1 - коефіцієнт, що враховує, яка частина механічної енергії перетворюється в теплоту на шляху від насоса до конденсатора; 
Hw - тиск, який створюється насосом охолодного середовища (води):\

ךw - к.к.д насоса охолоджуючої води;

ךдв - к.к.д. електродвигуна цього насоса

Кількість ексергіi, яким повинен володіти потік холодоагенту на вході в повітроохолоджувач, тобто кількість ексергіi, що входить в третю зону термоекономіческой моделі складе:

$$
\mathrm{e}_{3}=Q_{\text {по }} \cdot\left(\frac{T_{o c}}{T_{o}}-1\right)
$$

Визначаємо поток ексергіi, яка виходить 3 першої зони з врахуванням

$$
e_{1}=e_{3}+\Delta e_{\Pi}
$$

Величина втрати ексергії ( $\Delta$ еп) при необоротному переході кількості теплоти перегріву (Qп) 3 рівня середньої температури робочого тіла (Тсп1) на рівень температури навколишнього середовища (Тос) складе:

$$
\Delta e_{\Pi}=Q_{\text {п }} \cdot\left(\frac{T_{o c}}{T_{\text {сп } 1}}-1\right)
$$

Кількісь ексергіi, підведеної до електродвигуна парового зволожувача складає:

$$
e_{\text {пу }}=\frac{Q_{\text {пз }} \cdot H_{\text {зв }}}{\left(c_{w} \cdot \gamma_{w} \cdot \Delta T_{\text {зв }} \cdot \eta_{w}-H_{\text {зв }}\right) \cdot \eta_{\text {дв }}}
$$

При оптимізації режимів роботи холодильної установки уточнюється температурний напор повітроохолоджувача та конденсатора відповідно.

Величини zij пропорційні вартості $\mathrm{Cij}$ відповідного елемента встаткування. У свою чергу, вартість Сіј залежить від розрахункового навантаження на даний пристрій. У першому наближенні ці залежності можна вважати лінійними.

Вартість кожного елементу обладнання представлена у вигляді поліноміальних рівнянь:

$$
\mathrm{Cij}=\mathrm{Aij}+\mathrm{Bij} \cdot \mathrm{Xij}
$$

Величини Xij представляють собою сумарну характеристику, через яку вибиралося відповідне обладнання; Aij ,Вij - емперичні коефіцієнти

Остаточний вираз для цільової функції стосовно до розглянутої холодильної установки складе 3 врвхуванням ночного, полупікового та пікового тарифів складає:

$$
\begin{aligned}
& \text { ПВ }=\left(Ц_{\text {ел }}\left(\mathrm{e}_{11}+\mathrm{e}_{13}+\mathrm{e}_{32}+\mathrm{e}_{42}\right)++Ц_{\mathrm{w}} \mathrm{V}_{\text {сва }}+\mathrm{z}_{11}+\mathrm{z}_{12}+\right. \\
& \left.\mathrm{Z}_{13}+\mathrm{Z}_{31}+\mathrm{Z}_{32}+\mathrm{Z}_{42}\right) \tau_{\mathrm{p}}
\end{aligned}
$$

де Vсва обємна витрата свіжої води.

Визначення проміжної вартості ексергії між зонами можливо за формулою: $\lambda_{1 i}=\left[\left(e_{11}+e_{13}\right) \cdot \bigsqcup_{e л}+\bigsqcup_{w} V_{c в a}+z_{11}+z_{12}+z_{13}\right] / e_{1}$

Ми враховували, що, на відміну від таких величин, як витрата води чи електроенергії, які змінюються безперервним чином, вартість устаткувань і, відповідно, величини нормативних відрахувань змінюються дискретно. Наприклад, при можливості вибору з десяти компресорів різної потужності і вартості величина z11 приймає десять різних значень. Тому повний цикл мінімізації приведених витрат проводиться в два етапи таким чином.

Спочатку мінімізуємо величину ПВ , вважаючи всі змінні, в тому числі і zij, безперервними (назвемо цей етап першого циклом мінімізації ) . Потім , визначивши оптимальні значення всіх параметрів , вибираємо найближчі до оптимальним значення zij 3 наявного в наявності дискретного ряду значень цих величин . Зафіксувавши обрані значення zij, проводимо мінімізацію повторно (рахуючи тепер zij постійними ). Назвемо цей етап другим циклом мінімізації . У другому циклі мінімізації визначається оптимальний режим роботи конкретної установки , обладнаної вибраними пристроями. Якщо ж оптимізується робота вже укомплектованої холодильної уста - новки, то необхідність у першому циклі мінімізації відпадає.

У другому циклі мінімізації величина $\mathrm{F}$ для теплообмінного обладнання передбачається заданої. Тому температурний напір тепер не $\epsilon$ незалежним параметром, а визначається за формулою (13) для повітроохолоджувача та за формулою (29) для конденсатора.

$$
\Theta_{\mathrm{K}}=\frac{\mathrm{Q}_{\mathrm{K}}}{\mathrm{k}_{\mathrm{K}} \cdot \mathrm{F}_{\mathrm{K}}} .
$$

В роботі при вирішенні задач оптимізації був використаний чисельний метод, який не вимагає диференціювання цільової функції, на відміну від рішень, в яких використовуються класичні методи диференціального і варіаційного обчисленні

\section{III. ВИСНОВКИ}

Для кожного набору основних величин, що характеризують режим роботи установки (температура охолоджуючої води, температура переохолодження робочого тіла в конденсаторі і т.п.) обчислювалися оптимальні значення параметрів.

3 розрахунків випливає, що змінна частина приведених витрат в області допустимих значень параметрів може варіюватися на 9 -13\%.

Отримані залежності рішення термоекономічної моделі оптимізації одноступеневої установки можливо застосувати для підвищення ефективності, як системи охолодження плодоовочесховищ, так у системах кондиціювання повітря шляхом мінімізації величини приведених витрат. 
Результати досліджень були використані Інженерно-технологічним інститутом «Біотехніка» Національної академії аграрних наук Украіни при роботі над темою «Розробити наукові та інженерно-технологічні основи створення багатоцільових біолого-кліматичних комплексів нового покоління для одержання та зберігання препарату захисту рослин, фізичного моделювання технологій захисту рослин» .

Розроблена термоекономічна модель оптимізації режимів роботи та при проектуванні сучасних систем кондиціонування повітря фірмами «Ейр Інжинірінг» (м.Київ), ТОВ «МТЕСН СЕР$\mathrm{BIC»} \mathrm{(м.Харків),} \mathrm{МПП} \mathrm{«СМК»} \mathrm{(м.Керч).}$

\section{ЛІТЕРАТУРА}

1. Оносовский В.В. Моделирование и оптимизация холодильных установок. - Ленинград: Издательство Ленинградского университета, 1990. $205 \mathrm{c}$.
2. Грачев Ю.Г. Основы оптимизации систем кондиционирования микроклимата.-Пермь, изд. Перм, политехн.ин-та, 1987, 80с.+ 1 вкл.

3. Аль-Ахрас Гассан. Теплофизические аспекти холодильного хранения плодоовощной продукции в условиях жаркого климата. Автореф дис. канд. техн. наук.- Одесса, 1999, 23 с.

4. Жихарєва Н.В., Хмельнюк М.Г. Повышение эффективности системы охлаждения плодоовощехраниш. - Вестник международной академии холода 2013. - Вып 4 - с. 16-20.

5. Жихарєва Н.В., Хмельнюк М.Г. Оптимізація режиму роботи холодильної установки плодоовочесховищ. - Холодильна техніка та технологія 2012. № 5 (139) - c. 16-20.

6. Жихарєва Н.В., Хмельнюк М.Г. Термодинамічний аналіз ефективності судових холодильних установок. Електронне видання «Вісник Національного университету кораблебудування»: Миколаїв. НУК, - 2012. №2. Режим доступу: http://ev.nuos.edu.ua/ua/issue?issueId=17919

\section{N.V. Zhikhareva}

Odessa National Academy of Food Technologies, Dvoryanskaya st., 1/3, Odessa, 65082

\section{MATHEMATICAL ASPECTS OF FRUIT-AND VEGETABLE STOREHOUSE REFRIGERAT- ING UNIT THERMOECONOMIC ANALYSIS}

Mathematical aspects of fruit-and vegetable storehouse refrigerating unit operating mode thermoeconomic analysis are considered in the study. The values of exergy flow end exergetic losses on the example of direct cooling refrigerating unit are determined..

Keywords: optimization - operating modes - refrigerating unit - thermoeconomic model exergy-exergetic losses.

\section{REFERENCES}

1. Onosovskiy V.V. Modelirovanie I optimizatsiya kholodilnikh ustanovok. - Leningrad: Izdatelsnvo Leningradskogo universiteta, 1990. $-205 \mathrm{p}$.

2. Grachev Yu.G. Osnovy optimizatsii system konditsionirovaniya mikroklimat. - Perm': izd. Perm. politekn. instituta, 1987, 80 p.+ 1 vkl.

3. Al-Akhras Gassan. Teplofizicheskie aspekti kholodil'nogo khraneniya plodoovoshchnoy produktsii v usloviyakh zharkogo klimata. Avtoref dis. kand. tekhn. nauk.-- Odessa, 1999, 23 p.

3. Zhikhareva N.V., Khmelniuk M.G. Povyshenie effektivnosti sistemy okhlazhdeniya plodoovo shchekhranish. - Vestnik mezhdunarodnoy akademii kholoda, 2013. - Vyp. 4 - p. 16-20.

4. Zhikhareva N.V., Khmelniuk M.G. Optimizatsiya rezhimu roboti kholodil'noï ustanovki plodoovocheskhovishch. - Kholodil'na tekhnika ta tekhnologiya - 2012. № 5 (139) - p. 16-20.

5. Zhikhareva N.V., Khmelniuk M.G. Termodinamichnij analiz efektivnosti sudovih kholodil'nikh ustanovok. Elektronne vidannja «Visnik Nacional'nogo universitetu korablebuduvannja»: Mikolaïv. NUK, - 2012. №2. Rezhim dostupu: http://ev.nuos.edu.ua/ua/issue?issueId=17919

Отримана в редакції 07.02.2014, прийнята до друку 04.03.2014 